\title{
Catadores e movimento social: uma pesquisa bibliométrica
}

\author{
Collectors and the social movement: A bibliometric survey
}

Gleiciane Rosa da Silva1 ${ }^{1}$, Maria Zanin²

${ }^{1}$ Universidade de São Paulo

${ }^{2}$ Universidade Federal de São Carlos

RESUMO: O objetivo do presente trabalho é demonstrar importância do tema estudado, mediante pesquisa bibliográfica empreendida, tendo como objeto, pesquisas que empregaram os termos "Movimento Social" e "Catadores de Materiais Recicláveis" e seus respectivos correlatos, na base de dados CAPES, no período compreendido entre os anos de 2010 a 2012. Para isso foi indispensável conceituar ambos os termos, por meio de publicações com reconhecimento científico atestado. A pesquisa bibliométrica apontou para as peculiares das publicações e permitiu uma análise pormenorizada da justificativa sobre a importância da temática movimento social de catadores de materiais recicláveis no campo científico, conceituado no trabalho como ferramenta de divulgação e reivindicação de direitos sociais, por ora renegados pela sociedade brasileira, cuja desigualdade social alimenta a exclusão.

PALAVRAS CHAVE: movimento nacional de catadores, movimento social, catadores.
ABSTRACT: The purpose of this study is to demonstrate the importance of the subject studied by undertaken literature, with the object, research that employed the terms "Social Movement" and "Recyclable materials" and their correlates in the CAPES database, the period between the years 2010 to 2012. this was essential to conceptualize both terms, through publications with scientific recognition certificate. The bibliometric research pointed to the peculiar publications and allowed a detailed analysis of the justification of the importance of thematic social movement of waste pickers in the scientific field, regarded the work as marketing tool and claim social rights, for now disowned by society Brazilian, whose social inequality feeds exclusion.

KEYWORDS: national movement of collectors, social movement, collectors.

\section{Correspondência}

${ }^{1}$ Gleiciane Rosa da Silva

Universidade de São Paulo

São Paulo, SP.

Email: gleici.any@hotmail.com

ORCID: http://orcid.org/0000-0001-9210-6467

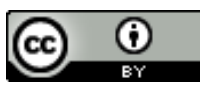

JITA: BB. Bibliometric methods. 


\section{INTRODUÇÃ̃O}

Ao tentar definir o termo "movimento social" nos deparamos com uma lacuna. Segundo Gohn (1997) soma-se a isso indiferenciação entre movimentos de múltiplos tipos e dificuldade de caracterizá-los como tal dentre lutas, protestos, revoluções, quebra-quebras, insurreições dentre outras ações coletivas. As teorias a respeito apresentam um leque de entendimentos. Para alguns trata-se de um fenômeno empírico, para outros de objetos analíticos, teóricos. Não há um conceito, mas alguns, segundo seu paradigma, classificados segundo aqui geopoliticamente, pois a América do Norte, a Europa e América Latina possuem contextos históricos específicos e movimentos sociais em reposta a elas. Com o advento da globalização, estes contextos foram se alterando, gerando aglutinações e foi possível encontrar características gerais nos anos 90 .

Do paradigma norte-americano extrai-se a preocupação com estruturas das organizações, com destaque para análise de categorias tais como: sistemas, ação coletiva, comportamentos organizacionais, integração social etc. de onde derivaram analises como a da mobilização de recursos, institucionalização de conflitos, ciclos de protestos, micromobilizações e oportunidades políticas. Na Europa faz-se necessária diferenciar os paradigmas Marxista e dos Movimentos Sociais, cada qual com suas subdivisões e teorias. A marxista estuda os processos históricos globais tendo em vista as contradições e as lutas de classe. São categorias: classes sociais, contradições, lutas, experiências, consciência, conflito, interesses de classes, reprodução da força de trabalho, Estado etc. O paradigma dos Novos Movimentos Sociais procura explicações mais conjunturais, retiradas do âmbito político ou dos microprocessos da vida cotidiana, fazendo recortes na realidade para observar a política dos novos atores sociais. Apresenta as categorias básicas: cultura, identidade, autonomia, subjetividade, atores sociais, cotidiano, representações, interação política etc.

\footnotetext{
$\mathrm{O}$ paradigma latino americano concentrou-se quase todo em movimentos sociais libertários ou emancipatórios, de índios, negros, mulheres e minorias em geral, nas lutas populares urbanas por bens e equipamentos coletivos, ou espaço para moradia urbana (nas associações de moradores e nas comunidades de base da igreja e nas lutas pela terra, na área rural). (GOHN, 1997, pag. 15)
}

As teorias que os orientavam eram as europeias, tendo predominado as marxistas nos anos 70 e a abordagem dos Novos Movimentos Sociais nos anos 80. Para as teorias marxistas houve o destaque para as categorias: hegemonia, contradições urbanas e lutas sociais. Para as teorias dos Novos Movimentos Sociais a autonomia e a identidade receberam ênfase, mas que resultaram na criação de outras como novos sujeitos históricos, campo de força popular, cidadania coletiva, espoliação urbana, exclusão social, descentralização, espontaneidade, redes de solidariedade, setor terciário privado e público etc. Essas novas categorias apontam para o desenvolvimento de um paradigma próprio, mas que esbarra em dilemas. Nos países latino-americanos, os problemas gerados pela globalização da economia, como o incentivo ás políticas econômicas neoliberais ocasionou o surgimento de redes produtivas comunitárias. 


\section{O MOVIMENTO NACIONAL DOS CATADORES DE MATERIAIS RECICLÁVEIS}

A função de catadores de materiais recicláveis surge no Brasil diante de um quadro de extrema pobreza, relativo ao modo capitalista que estabelece relações de desigualdade em face aos padrões de competitividade, que deixa a margem da sociedade um contingente de pessoas que não possuem os requisitos necessários para conquistarem espaço no mercado formal de trabalho. Dessa forma deriva-se o subemprego, as condições precárias de trabalho e o subsequente aumento da violência, criminalidade, dentre outras dificuldades que obrigam a busca de alternativas de sobrevivência digna, em face a esse cenário insustentável (CRUZSOUZA, 2011, KLINSBERG, 2002)

Diante da necessidade de sobrevivência imediata, a atividade de catação passou a ser desenvolvida nas áreas urbanas das cidades brasileiras por pessoas espalhadas pelas cidades, que retiram do "lixo", materiais que possam ser reutilizados ou reciclados. Assim, surgem os catadores, que mesmo estigmatizados pela sociedade e com dificuldades que incluem a exploração por parte de empresários, denominados sucateiros ou atravessadores que compram o material coletado por preços ínfimos, seguem um caminho que os leva a uma organização social. Uma evidência disso é a formação do movimento social que representa a classe (GUTIERRES, ZANIN, 2011).

O Movimento Nacional de Catadores Materiais Recicláveis é um movimento social que busca organizar os catadores por todo o país, a valorização da classe sob os princípios da autogestão, ação direta, independência de classe, solidariedade de classe, democracia direta e apoio mútuo (MNCR, 2013).

Um fato histórico que marca o surgimento do Movimento Nacional de Catadores de Materiais Recicláveis (MNCR, 2013) foi o primeiro encontro Nacional de Catadores de Papel, em 1999. Outro fato foi o primeiro congresso Nacional de Catadores de Materiais Recicláveis, ocorrido em Brasília em junho de 2001e é considerado o marco da fundação deste Movimento (MNCR, 2013). A mobilização para este evento reuniu mais de mil e setecentos catadores e catadoras e culminou com o lançamento da Carta de Brasília, documento que exprime as necessidades das pessoas que sobrevivem da coleta de materiais recicláveis (MNCR, 2013).

O movimento que conta com mais de dez anos de luta, comemora resultados e vem organizando pessoas por todo o Brasil, mas ainda coexiste com a realidade dos catadores que trabalham em lixões e nas ruas em condições precárias. Porém, hoje os catadores teem sua voz ampliada e ouvida em vários espaços. Exemplo das conquistas do MNCR e considerada sua principal contribuição, é o reconhecimento do catador de material reciclável como uma categoria de trabalho pela Classificação Brasileira de Ocupações (CBO) a partir de 2002 (CBO, 2002), ainda que a atividade de catação tenha surgido no mundo do trabalho há pelo menos cinquenta anos (MNCR, 2013).

No âmbito das políticas púbicas que favorecem a ocupação, está a assinatura do Decreto que cria o Comitê Interministerial da Inclusão Social de Catadores de Lixo, em 11 de 
setembro de 2003 (FERREIRA, 2008) e o Decreto $\mathrm{n}^{\circ}$ 5.940, de 25 de outubro de 2006, que busca incluir o catador de forma legal, visando garantir que os materiais recicláveis sejam destinados a associações e cooperativas. O Decreto ("institui a separação dos resíduos recicláveis descartados pelos órgãos e entidades da administração pública federal direta e indireta, na fonte geradora, e a sua destinação às associações e cooperativas dos catadores de materiais recicláveis, e dá outras providências.”) (GUTIERREZ e ZANIN, 2011).

\subsection{A Pesquisa Bibliométrica}

Este trabalho foi realizado utilizando a base de teses e dissertações da CAPES, onde encontram-se disponíveis apenas as pesquisas referentes aos anos de 2011 e 2012, para a realização de uma pesquisa bibiométrica. Inicialmente escolhemos a temática e classificamos seus termos correlatos e quantificamos sua ocorrência no título e na palavra-chave das teses. Após encontrar as dissertações e teses que apresentam relação entre os termos, fizemos a leitura dos resumos para assegurar que a proximidade com a temática "Movimento Social de Catadores de Materiais Recicláveis".

Figura 1. Termos da pesquisa bibliométrica

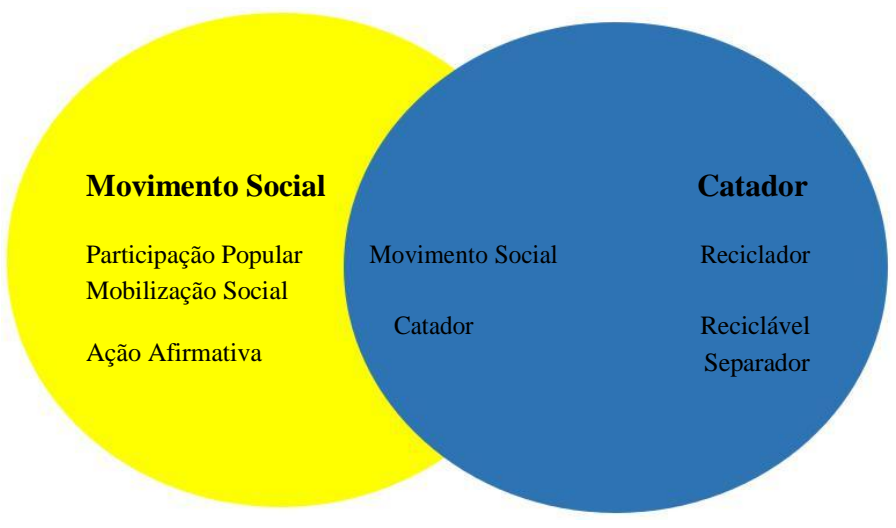

Fonte: Elaborada pelas autoras.

Como pode ser observado na Figura 1, os termos pesquisados foram acrescidos dos seus correlatos, para que pudéssemos encontrar todos os trabalhos que abrangem as temáticas.

O termo "Catador", por exemplo, que refere-se a atividade de catação de materiais recicláveis, aparece em apenas uma tese, enquanto que "Reciclador" foi encontrado em três trabalhos. Os termos foram buscados também observando o número e o gênero das palavras. Para "Catador" pesquisamos: "Catador", "Catadora", "Catadores" e "Catadoras". A busca está descrita a seguir.

Bloco A: Movimento Social - também foram procurados: "Participação Popular", "Mobilização Social”, "Ação Afirmativa". 
Bloco B: "Catador"," Reciclador", "Reciclagem", "Reciclável” e "Separador".

A Tabela 1 apresenta o resultado final da busca empreendida, a partir da qual foi possível encontrar as intersecções entre as teses.

Tabela 1. Teses encontradas segundo cada bloco de termos

\begin{tabular}{ccc}
\hline Bloco & Termo & Banco de Teses Capes \\
\hline Bloco A & Movimento Social & 1520 \\
Bloco B & Catador & 144 \\
& Reciclador & 3 \\
\hline
\end{tabular}

Fonte: elaborada pelas autoras com base em pesquisa empreendida no Banco de Teses da CAPES em 14 de janeiro de 2016.

\subsection{Análise de aspectos encontrados}

A partir da pesquisa bibliométrica que teve como objeto o conjunto de teses utilizado pelo o banco de dados da CAPES, referente a 2011 e 2012, podemos proceder com algumas análises.

a) Foram encontradas duas dissertações com a intersecção dos termos principais

"Movimento Social" e "catador", ou mesmo "reciclador", o que indica a importância desse estudo para o campo científico com vistas a divulgar o assunto.

b) Analisando os termos isoladamente, "Catador" aparece cento e quarenta e quatro vezes, enquanto o termo "Reciclador" está presente em apenas três pesquisas. As pesquisas encontradas abordam a principalmente estudos e caso de cooperativas de catadores, com enfoque principalmente na formação e organização, adotando como referenciais a Educação Popular e a Economia Popular ou Solidária, o que demonstra uma aproximação com a temática desse importante e número contingente de brasileiros que buscam a inclusão social por meio de processos emancipatórios, associando-se e procurando trabalhar de forma cooperada, construída por meio de processos democráticos. Há necessidade ainda de muito estudo sobre a temática, de modo a contribuir com a organização dos catadores e a garantia dos seus direitos sociais.

c) O assunto "Movimento Social" por sua vez, figura em um número expressivo de pesquisas. São mil quintas e vinte teses e dissertações voltadas para estudar o fenômeno em suas diversas motivações. Aparecem os movimentos que angariam transformações em campos da sociedade brasileira: ligados à questão agrária, como o MST, educação, direitos dos negros, índios, mulheres, 
diversidade sexual, movimentos culturais, portadores de deficiências, dentre muitos outros.

d) Duas motivações se destacam como as mais pesquisadas, as questões agrárias e a educação para vários públicos. São trinta e duas teses abordando as questões agrárias.

\section{CONCLUSÃ̃}

Após as análises consideramos que o tema proposto neste trabalho prescinde de atenção do meio científico, em especial na área da educação, para que os movimentos sociais e os catadores de materiais recicláveis possam ser enxergados pela sociedade. A função da ciência no campo social pode ser transformadora e um importante apoio para a legitimação das populações empenhadas na conquista dos seus direitos. Acreditamos que pesquisas sobre o Movimento Nacional dos Catadores de Materiais Recicláveis (MNCR) são necessárias e urgentes para contribuir com essa organização legitima que recebe apoio das universidades brasileiras por meio de projetos de extensão e outras ações. Os catadores organizados pelo movimento já foram capazes de alcançar uma importante vitória que foi o reconhecimento enquanto profissão e trabalha sem cessar prol de novas conquistas.

\section{COLECCIONISTAS Y MOVIMIENTO SOCIAL: UN ESTUDIO BIBLIOMÉTRICO}

RESUMEN: El objetivo de este estudio es demostrar la importancia del tema estudiado por la literatura llevado a cabo, con el objeto, la investigación que emplea los términos "movimiento social" y "materiales reciclables" y sus correlatos en la base de datos CAPES, el periodo comprendido entre los años 2010 a 2012. esto era esencial para conceptualizar ambos términos, a través de publicaciones con certificado de reconocimiento científico. La investigación señaló bibliométrico de las publicaciones peculiares y permitió un análisis detallado de la justificación de la importancia de la temática movimiento social de los recicladores en el campo científico, considerado el trabajo como herramienta de marketing y reclamar los derechos sociales, por ahora repudiado por la sociedad brasileña, cuya desigualdad social alimenta la exclusión.

PALABRAS ClAve: Movimiento nacional de los colectores, Movimiento social, Colectores.

Submetido em: 24/04/2016

Aceito em: 11/07/2016

Publicado em: 03/11/2016 


\section{REFERÊNCIAS}

GOHN, M. G. M. Teria dos Movimentos Sociais: Paradigmas Clássicos e Contemporâneos. São Paulo: Loyola, 1997

GUTIERREZ, R. F. e ZANIN, M. Empreendimentos Econômicos de Catadores de Resíduos e Legislações Vigentes: Avanços e Limites Gerais: Revista Interinstitucional de Psicologia, 4 (2), Edição Especial, dezembro, 2011, p. 113-121.

FERREIRA, E. Dinâmicas de apropriação do conhecimento por famílias de catadores de material reciclável: políticas públicas, projetos e tecnologias sociais. Dissertação de Mestrado. Universidade Tecnológica Federal do Paraná, Curitiba, 2008.

CLASSIFICAÇÃO BRASILEIRA DE OCUPAÇÕES (2002). Disponível em $<$ http://www.mtecbo.gov.br> Acesso em: 13 nov. 2014.

MNCR: MOVIMENTO NACIONAL DOS CATADORES DE MATERIAIS RECICLÁVEIS. Disponível em <http://www.mnrc.org.br> Acesso em: 13 nov. 2014.

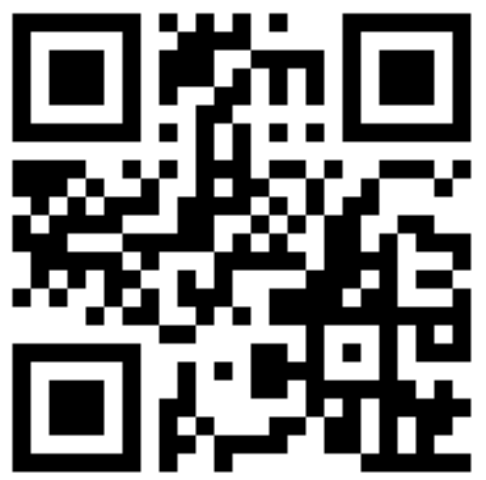

